\title{
Percutaneous Therapies for Hepatocellular Carcinoma: Evolution of Liver Directed Therapies
}

\author{
Timothy C Huber \\ Teodora Bochnakova \\ Yilun Koethe \\ Brian Park (D) \\ Khashayar Farsad
}

Dotter Department of Interventional Radiology, Oregon Health and Science University, Portland, OR, USA
Correspondence: Khashayar Farsad Email farsad@ohsu.edu

\begin{abstract}
Percutaneous ablation is a mainstay of treatment for early stage, unresectable hepatocellular carcinoma (HCC). Recent advances in technology have created multiple ablative modalities for treatment of this common malignancy. The purpose of this review is to familiarize readers with the technical and clinical aspects of both existing and emerging percutaneous treatment options for HCC.
\end{abstract}

Keywords: hepatocellular carcinoma, ablation, microwave, radiofrequency, electroporation, nanoparticles, cryoablation

\section{Introduction}

Hepatocellular carcinoma (HCC) is the second leading cause of cancer-related mortality worldwide, the fifth most common cancer in men, and the seventh most common cancer in women. ${ }^{1}$ Liver-directed therapies (LDT), including both percutaneous and transarterial approaches, are first-line therapy options for early and intermediate stage HCC for those with unresectable disease, or as a therapeutic bridge for those awaiting liver transplantation. Increasing experience and interest with external beam radiation therapy is also evolving as a noninvasive locoregional treatment option for suitable candidates with limited treatment options. Moreover, newer systemic therapies have emerged for advanced stage disease.

Thermal ablation has historically been the mainstay of percutaneous LDT in early stage, unresectable HCC. Both heat and ice-based ablation techniques exist, including radiofrequency ablation (RFA) and microwave ablation (MWA), and cryoablation. These techniques have primarily supplanted direct intra-tumoral chemical injection. Newer technologies including irreversible electroporation (IRE), histotripsy, and high intensity focused ultrasound (HIFU) show promise but have not yet been widely adopted in clinical practice.

This review will focus on the current state of percutaneous locoregional therapies and future directions that may benefit patients in the years to come. In performing this review, articles were selected from a PubMed search (https:// pubmed.ncbi.nlm.nih.gov) using several pertinent terms including hepatocellular carcinoma, percutaneous, ablation, ethanol, acetic acid, injection, microwave, radiofrequency, cryoablation, nanoparticles, irreversible electroporation. Articles included span from 1995 to 2021, including primary literature for case-series, prospective trials, benchtop and translational studies, meta-analysis and 
comprehensive review articles. A total of 94 references were ultimately curated to conduct this review.

\section{How Do We Decide Who to Treat? Patient Selection}

Before treatment, clinicians typically evaluate liver function using the Child-Turcotte-Pugh (CTP) classification or the Model for End-Stage Liver Disease (MELD) score. The functional status of the patient is typically also assessed by using the Eastern Cooperative Oncology Group (ECOG). These metrics have consistently been shown to correlate with outcomes and survival. ${ }^{2-4}$

Published consensus guidelines for HCC outcomes after LDT assume relatively preserved liver function (CTP A) and good performance status (ECOG 0). Caution is advised when attempting to extrapolate these outcomes to patients with worse liver function or performance status. ${ }^{2}$

Due to the high degree of institutional variation in practice, considerations for liver transplantation, and a variety of currently open clinical trial options, HCC patients are frequently discussed at multidisciplinary tumor boards for consensus on optimal therapy.
Performance status and Child-Pugh score are combined with radiologic tumor characteristics to determine the optimal treatment. The Barcelona clinic liver cancer (BCLC) staging system is one of the most widely used for HCC, incorporating treatment recommendations by stage. ${ }^{5}$ Pretreatment cross-sectional imaging with unenhanced and multiphasic enhanced $\mathrm{CT}$ or MRI is performed to diagnose $\mathrm{HCC}$ and to evaluate tumor size, number of tumors, vascular invasion, and extra-hepatic spread. For percutaneous therapies such as ablation, choice of treatment modality depends on local expertise and operator preference. Each ablation technique has advantages and disadvantages, and tumor size and location may demand special considerations or adjunct maneuvers to optimize treatment and minimize risk to the patient (see Table 1). For tumors in high-risk locations such as along the diaphragm, near the gallbladder fossa, or adjacent to bowel, local expertise with specialized maneuvers must be weighed against surgical candidacy. Most ablative therapies are performed either under moderate sedation or general anesthesia. Patient assessment for procedural sedation risk, such as with the American Society of Anesthesiologists (ASA) classification score, is also critical.

Table I Comparison of Percutaneous Ablation Modalities

\begin{tabular}{|c|c|c|c|c|c|}
\hline & Radiofrequency Ablation & $\begin{array}{l}\text { Microwave } \\
\text { Ablation }\end{array}$ & Cryoablation & $\begin{array}{l}\text { Percutaneous } \\
\text { Ethanol Injection }\end{array}$ & $\begin{array}{l}\text { Irreversible } \\
\text { Electroporation }\end{array}$ \\
\hline Pros & $\begin{array}{l}\text { Widely available } \\
\text { Large body of literature } \\
\text { Variety of electrode shapes }\end{array}$ & $\begin{array}{l}\text { Faster treatment } \\
\text { time } \\
\text { Fewer antennas } \\
\text { needed } \\
\text { Larger ablation } \\
\text { zone }\end{array}$ & $\begin{array}{l}\text { Can visualize } \\
\text { ablation zone } \\
\text { Can be done } \\
\text { without GA }\end{array}$ & Less expensive Fast & $\begin{array}{l}\text { Can treat hilar } \\
\text { tumors } \\
\text { Can treat tumors } \\
\text { near bowel }\end{array}$ \\
\hline Cons & $\begin{array}{l}\text { Heat sink } \\
\text { Monopolar requires grounding pads }\end{array}$ & $\begin{array}{l}\text { Not as widely } \\
\text { available }\end{array}$ & $\begin{array}{l}\text { Longer } \\
\text { procedure time } \\
\text { Multiple probes } \\
\text { often required } \\
\text { Less data on } \\
\text { efficacy } \\
\text { Higher risk of } \\
\text { bleeding } \\
\text { Possible } \\
\text { cryoshock }\end{array}$ & $\begin{array}{l}\text { Can require multiple } \\
\text { treatments } \\
\text { Non-uniform infusion }\end{array}$ & $\begin{array}{l}\text { Requires precise } \\
\text { electrode } \\
\text { positioning } \\
\text { At least } 2 \\
\text { electrodes requirec } \\
\text { High cost } \\
\text { Limited to smaller } \\
\text { tumors }\end{array}$ \\
\hline $\begin{array}{l}\text { Patient } \\
\text { selection }\end{array}$ & $\begin{array}{l}\text { Single session: Tumor } 3 \mathrm{~cm} \text { or less* } \\
\text { Consider switching monopolar RFA with } \\
2-6 \text { electrodes for tumors }>3 \mathrm{~cm}\end{array}$ & $\begin{array}{l}\text { Single session: } \\
\text { Tumor } 3 \mathrm{~cm} \text { or } \\
\text { less* }\end{array}$ & $\begin{array}{l}\text { Can treat larger } \\
\text { tumors }\end{array}$ & $\begin{array}{l}\text { Not frequently } \\
\text { performed } \\
\text { Can be used if thermal } \\
\text { ablation is not feasible }\end{array}$ & $\begin{array}{l}\text { Tumors near hilum, } \\
\text { gallbladder fossa } \\
\text { Tumor }<5 \mathrm{~cm}\end{array}$ \\
\hline
\end{tabular}

Notes: *Tumors larger than $3 \mathrm{~cm}$ can be treated, but may require multiple electrodes/antennas for a single session, or multiple treatments due to residual disease. A $3 \mathrm{~cm}$ tumor can be consistently treated with adequate margins across modalities. 


\section{What Techniques are We Using Today?}

\section{Percutaneous Ethanol Injection/Chemical Ablation}

Percutaneous ethanol injection (PEI) was one of the initial ablative techniques employed for treatment of HCC, and it has shown efficacy for small solitary tumors $\leq 2 \mathrm{~cm}$. Ethanol $(95-99.5 \%)$ is a caustic agent that is directly injected into tumors to cause cell death. Ethanol works not only directly by denaturing proteins in tumor cells, but also by causing local thrombosis. The procedure is fast and relatively inexpensive compared to other ablation techniques; however, it can be difficult to ensure appropriate delivery of ethanol for complete tumor coverage due to heterogeneity within the tumor architecture. Once injected, the tumor capsule contains the ethanol as it does not spread easy through fibrous septa or the tumor capsule. Acetic acid is another infused agent for tumor treatment that has been shown to be lethal to hepatocytes. Percutaneous acetic acid injection (PAI) using a 50\% solution of acetic acid has the ability to treat HCCs effectively because it appears to penetrate intra-tumoral collagenous septa more effectively than ethanol.

\section{Technical Considerations}

$\mathrm{PEI} / \mathrm{PAI}$ is commonly performed under ultrasound guidance or in combination with CT fluoroscopy. A 21 or 22gauge needle is advanced to the deep portion of the tumor. The agent is injected while the needle is retracted to infuse a segment of the tumor. For tumors larger than $2 \mathrm{~cm}$, this must be repeated several times to ensure adequate coverage of the entire tumor. In general, $5-10 \mathrm{~mL}$ of agent is used per session. Specialized delivery devices have also been incorporated to improve infusion efficiency. As the needle is withdrawn from the tumor, gelatin sponge or saline is injected to minimize leakage of ethanol into the surrounding liver parenchyma.

\section{Efficacy and Outcomes}

Small series have compared PEI and PAI, but data are insufficient in aggregate to suggest a significant difference in terms of outcomes. ${ }^{8,9}$ Recurrence is common due to insufficient control of the spread of the agent, inhomogeneous distribution in larger tumors, and difficulty attaining adequate treatment margins. While chemical ablation with ethanol and acetic acid has demonstrated efficacy for treating small HCC, the introduction of thermal ablation has largely replaced this technique based on improved outcomes and fewer limitations, particularly for tumors $>2 \mathrm{~cm}^{8}{ }^{8}$ PEI remains a useful technique in select cases, or for targeting a portion of tumor adjacent to critical structures at risk for thermal injury.

\section{Radiofrequency Ablation}

\section{Technical Considerations}

Radiofrequency ablation is a hyperthermal ablative technique that causes coagulative necrosis and cell death. Current is passed through a circuit including a generator, a monopolar electrode needle and large dispersive grounding pads typically located on the patient's thighs or back. The tissue to be ablated functionally acts as a resistor to complete the circuit. Bipolar systems also exist which do not require grounding pads, and allows operators to treat patients with pacemakers more safely. The applied current agitates ions around the tip of the electrode due to high local current density, causing local frictional heating that is then conducted deeper into the surrounding tissue. Irreversible heat-related cell injury and death can happen at temperatures $\geq 46$ degrees depending on the duration of heat application, with shorter application times required for higher temperatures. ${ }^{10}$ While there is likely extensive tissue variability with respect to thresholds for cell death, general clinical consensus for the liver suggests immediate cell death at temperatures between 60 and 100 degree Celsius, and cell death within 5-6 minutes of heat application above 50 degree Celsius. ${ }^{11}$ Ablation zones with RFA are significantly impacted by increased tissue impedance, which occurs with tissue desiccation and vaporization at higher temperatures. Different ablation systems and operator experience can address these issues to achieve an effective ablation.

Ablation zone shape is also increasingly controllable by operators. The majority of research into ablation zone shape has been done with RFA. Multi-tined electrodes allow the operator to control the size of the ablation zone by adjusting the surface area generating heat. ${ }^{12}$ Additionally, directional electrodes are being developed that either allow the operator to change the shape of the multi-tine array, or allow the operator to selectively heat only one side a single electrode. ${ }^{13}$ Switching monopolar RFA (SW-RFA) uses a 2-6 electrode array and alternating activation of the electrodes to produce a larger ablation zone than single electrode RFA. A recent study by Lin 
et al comparing SW-RFA to single electrode RFA demonstrated similar long-term outcomes for $\mathrm{HCC}<3.5 \mathrm{~cm}$, but superior outcomes with SW-RFA for HCC measuring $>3.5 \mathrm{~cm} .{ }^{14}$ All of these advances may allow for safer and more effective treatment of tumors that are larger, near the hilum, or near large vessels.

\section{Efficacy and Outcomes}

RFA has been more extensively studied than other ablation modalities. Short- and medium-term survival after RFA of HCC is generally high, especially in patients with solitary or small tumors. For very early-stage HCC (BCLC 0), cohort studies and meta-analyses have observed outcomes for RFA rivaling resection, with $>70 \% 5$ year survival rates and putatively with lower cost. ${ }^{2,15}$ Doyle et al reported 1, 3, and 5 year survival for tumors $<2 \mathrm{~cm}$ as $98.2 \%, 86.2 \%$, and $79 \%$; and $2-3 \mathrm{~cm}$ tumors as $93.3 \%$, $77.6 \%$, and $70.9 \%{ }^{16}{ }^{16}$ 'Kontchou et al evaluated outcomes after RFA for patients with single tumors up to $5 \mathrm{~cm}$ or three tumors up to $3 \mathrm{~cm}$, reporting a $40 \% 5$ year survival, a $17 \%$ recurrence free survival, and a $32 \%$ tumorfree survival. ${ }^{17}$ However, in a subgroup analysis of patients meeting BCLC criteria for resection, the 5 year overall survival was significantly higher at $76 \%$, highlighting the importance of tumor size on outcomes.

\section{Safety and Complications}

With appropriately selected patients, RFA is a safe and well-tolerated procedure. Major complication rates are low, between $2 \%$ and $10 \%$ with procedure-related mortality rates $<1 \%{ }^{18,19}$ In a study of 664 patients undergoing 1000 ablations for HCC with RFA, Tateishi et al reported a major complication rate of $4 \%$, most of which were related to hemorrhage and hepatic abscess formation in the short term and track seeding in the longer term. ${ }^{20}$ Other major complications of RFA include perforated viscus, hepatic infarction, liver failure, biliary injury and pneumothorax. Skin burns have become quite rare due to efforts including limitation of applied power, maximizing dispersive surface area using multiple grounding pads and ensuring an equal distance from the pads to the electrodes. ${ }^{19}$

\section{Challenges}

RFA does have limitations that must be considered for effective use. Current technology and safety constraints around power input somewhat limit ablation volumes for treating larger tumors, and outcomes are consistently best for tumors $<3 \mathrm{~cm} .{ }^{2}$ Furthermore, RF energy is susceptible to heat sink effects from adjacent vessels that can prevent lethal temperatures at tumor margins. Finally, caution must be taken around central tumors within $1 \mathrm{~cm}$ of major biliary ducts near the hilum to avoid biliary injury and subsequent biliary strictures. ${ }^{19}$

\section{Microwave Ablation}

\section{Technical Considerations}

Compared to RFA, MWA uses higher energy electromagnetic waves and frequencies to heat tissue and kill tumor cells. Each microwave ablation device functions as an antenna transmitting oscillating microwave energy to polar water molecules resulting in tissue heating. ${ }^{21}$ Microwave energy is distinct from RF in that it can propagate through a variety of tissues, including highimpedance, desiccated and charred substances. Existing medical devices generate microwaves between $915 \mathrm{MHz}$ and $2.45 \mathrm{GHz}$, corresponding to microwave tissue penetration between 2 and $4 \mathrm{~cm} .{ }^{21}$ Unlike radiofrequency techniques, microwave energy allows for active heating throughout the ablation zone, relying less on passive tissue conductance to transmit thermal energy. This property allows for faster treatments with MWA of a larger volume of tissue compared to RFA. As a result of this active heating, microwave ablation is also less susceptible to heat sink effects from nearby vasculature. ${ }^{22}$

\section{Efficacy and Outcomes}

MWA is a newer modality compared to RFA, with fewer studies that have evaluated long-term outcomes. Progression-free survival is reported to be between $27 \%$ and $91.7 \%$ at 3 years. ${ }^{23}$ In a recent meta-analysis by Cui et al comparing MWA to RFA, no significant difference was observed in overall survival or progression-free survival at 3 years. ${ }^{24}$

Based on the principles of heat-induced cell death utilized in MWA and RFA, both systems should perform similarly, with the potential added benefits of reduced treatment times and larger ablation zones with MWA. As a result, MWA has rapidly gained popularity as a dominant ablation modality for HCC.

\section{Safety and Complications}

Microwave ablation has similar complications to RFA including hemorrhage, pneumothorax, bowel perforation, and biliary injury. A multicenter trial in Italy reported 
a complication rate of $2.9 \%$ in 736 patients, with the most common major complications being symptomatic pleural effusion requiring drainage $(\mathrm{N}=3)$, intraperitoneal hemorrhage requiring transfusion $(\mathrm{N}=3)$, and bowel perforation requiring repair $(\mathrm{N}=2) .{ }^{18}$ The elliptical-shaped ablation zone and tissue dessication may result in non-target tissue injury. Furthermore, heterogeneities in system designs and implementation may result in more inconsistent ablation zones compared to the fairly reproducible ablations achieved with RFA. ${ }^{22}$

\section{Cryoablation Technical Considerations}

Modern cryoablation systems create ice via adiabatic cooling of gas by the Joule-Thomson effect. Argon gas rapidly cools as it expands, generating below-freezing temperatures in a small expansion chamber at the probe tip, creating a lethal ablation zone of ice between -20 and -40 degree Celsius via passive tissue conductance. Because the dispersion of low temperatures into tissue is passive, there is a direct relationship between the surface area of the probe and the cooling potential of the device. ${ }^{22}$ Hence, larger ablation zones require larger diameter probes. Modern designs have engineered smaller probes suitable for percutaneous insertion.

The 0 degree Celsius isotherm can be monitored by $\mathrm{CT}$, MR or US due to the relatively different tissue features of ice compared to water. Most cryoablation algorithms require sequential freeze-thaw cycles. Thawing can be passive or active by expansion of helium gas, which conversely warms via the Joule-Thomson effect. Cell death is achieved in a multifactorial process including mechanical disruption of cells, osmotic disruption of cellular homeostasis, and by microvascular thrombosis. ${ }^{25}$ There is some evidence that cell death with cryoablation is associated with greater inflammatory and more durable antitumor antigenic responses, raising interest in possible synergy of this technology with immunotherapy. ${ }^{26}$

\section{Efficacy and Outcomes}

While cryoablation is less commonly used to treat $\mathrm{HCC}$ than RFA or MWA, several studies have demonstrated its safety and efficacy. Rong et al evaluated 1197 HCC tumors within Milan criteria (mean diameter $2.9 \pm 0.9 \mathrm{~cm}$ ) treated with cryoablation reporting a $24.2 \%$ local recurrence at 5 years, and a $59.5 \%$ overall survival at 5 years. ${ }^{27}$ Of the patients who achieved complete response from cryoablation, $60.3 \%$ developed recurrence (local, distant intrahepatic, or extrahepatic). In a randomized multicenter prospective trial, Wang et al compared outcomes of RFA compared to cryoablation (180 patients in each arm) for patients with one or two HCC lesions $\leq 4 \mathrm{~cm}$. Despite cryoablation demonstrating lower recurrence rates, particularly for larger tumors $>3 \mathrm{~cm}$, no significant differences were noted in overall survival or tumor-free survival at 1 , 3 , or 5 years. $^{3}$

\section{Safety and Complications}

Complications are similar to those associated with RFA or MWA and include hemorrhage, pneumothorax, and infection. Major complication rates are similar between RFA and cryoablation. ${ }^{3,28}$ One notable complication associated with liver cryoablation is a complex systemic inflammatory response, termed "cryoshock," which can include multisystem organ failure, hemodynamic compromise, thrombocytopenia and disseminated intravascular coagulation. This is hypothesized to represent a cytokine response akin to that seen with sepsis and is in part related to the volume of liver subjected to cryotherapy. ${ }^{29,30}$ For this reason, cryoablation of the liver has not been as widely adopted as RFA or microwave ablation; however, careful patient selection and limitation of ablation volumes have been reported with favorable safety profiles. ${ }^{31,32}$

\section{Irreversible Electroporation}

\section{Technical Considerations}

Irreversible electroporation (IRE) is a non-thermal ablation technique used in locations where thermal ablation may be high risk. Through pulsations of high-energy electrical currents, IRE disrupts the cellular lipid bilayer, induces apoptosis, and causes cell death. However, the structural integrity of surrounding extracellular matrices is preserved.

IRE is advantageous over thermal ablative techniques for tumors within $1 \mathrm{~cm}$ of the major bile ducts, bowel and gallbladder, and large vessels. Because the current commercially available system (NanoKnife, AngioDynamics) only supports up to 6 monopolar probes, placed less than $2 \mathrm{~cm}$ apart, ablations are limited to tumors $<5 \mathrm{~cm}$. History of ventricular arrhythmia is a relative contraindication as the strong currents delivered during IRE ablation can trigger hemodynamically significant ventricular arrhythmias. IRE can be used for hilar or dome lesions, near adrenal glands, and near metallic stents as long as the 
metal is outside the ablation zone. ${ }^{33,34}$ General anesthesia with full muscle relaxation is required because the pulses will trigger surrounding skeletal muscle contractions.

While IRE overcomes the limitation of ablation adjacent to thermally sensitive structures, it can be technically more challenging. IRE requires a minimum of 2 monopolar probes to deliver electrical pulses, and requires approximately 3-5 probes for a 3-4 cm lesion. Because the probes function as capacitors across which an electrical current is applied, they must be parallel (max of 10 degrees in difference) and placed between 1.2 and $2.0 \mathrm{~cm}$ apart for maximum efficacy. These factors become particularly challenging when the operator must negotiate around the ribs. In such scenarios, ultrasound-guidance or navigational platforms can assist with more complex needle trajectory placements.

\section{Efficacy and Outcomes}

Both prospective and retrospective trials reporting HCCspecific data have demonstrated encouraging short-term outcomes. Short-interval follow-up of patients with HCC after IRE ablation have reported a $67-100 \%$ complete response rate. ${ }^{35-39}$ Other studies have reported local progression-free survival (LPFS) rates of $71-97 \%$ at 6 months, and $70-83 \%$ at 12 -months. ${ }^{36,40-42}$

Small tumor size is correlated with improved survival outcome. ${ }^{36}$ In a total of 23 patients with mean HCC size of $2.0 \mathrm{~cm}$ (range 1.0-5.0 cm), Freeman et al reported a 12month LRFS of $83.6 \%$ for all-comers, and $100 \%$ for HCC $<2.0 \mathrm{~cm}$. In addition, the median overall LPFS for tumors $<2 \mathrm{~cm}$ was 106.5 months compared to 34.5 months for all study patients. ${ }^{40}$

Only a few studies have observationally compared IRE to thermal ablation. Verloh et al reported a singleinstitution experience treating $47 \mathrm{HCC}$ with IRE and 117 HCC with MWA or RFA. Although their primary focus was not on response rate, the 6-week complete response rate was $84 \%$ in the MWA and RFA group compared to $67 \%$ in the IRE group. ${ }^{35}$ Bhutiani et al compared IRE and MWA ablation in 55 Child-Pugh B patients and reported no significant difference in complete response rate at 180days $(97 \%$ for 30 patients treated with IRE, $100 \%$ for 25 patients treated with MWA). ${ }^{42}$ Of note, the data described above are confounded by differences in cancer stage, Child-Pugh scores, and additional tumor directed therapy such as chemoembolization. A prospective randomized control trial would be needed to better evaluate the efficacy of IRE in HCC.

\section{Safety and Complications}

IRE of liver masses carries a similar rate of complication $(0-27.5 \%)$ compared to thermal ablation. ${ }^{43}$ Complications include intrahepatic abscess, hematoma/bleeding, portal vein thrombosis, arrhythmias, cholestasis, and lung injury (pleural effusion, pneumothorax, hemothorax). Verloh et al reported no differences in complication between IRE $(n=47)$ and MWA/RFA $(n=117)$ in HCC. ${ }^{35}$ In IRE, some complications are directly related to needing more probes and more complex trajectories. When IRE was first used, there were reports of cardiac arrhythmia. ${ }^{44}$ Recent device improvements with cardiac synchronization are included in all new models of NanoKnife (AngioDynamics), and reports of arrhythmia remain few.

Safe use of IRE for hepatic tumors encasing, abutting or within $1.0 \mathrm{~cm}$ of a vessel has been validated in numerous pre-clinical and clinical trials. Narayanan et al reported only $4.4 \%$ vascular changes in 158 vessels (average distance from vessel $2.3 \pm 2.5 \mathrm{~mm}$ ) evaluated in 129 lesions, 100 of which were hepatic masses. ${ }^{45}$ Similarly, mid-term outcomes report from Distelmaier et al reported no occlusion or narrowing after treating 43 tumors adjacent to major hepatic or portal veins. ${ }^{46}$ More recently, Shibuya et al evaluated small hepatic and portal veins. While they reported $37 \%$ portal and $27 \%$ hepatic vein occlusion, most involved veins $<4 \mathrm{~mm}$, and were not clinically significant. No hepatic vein $>4 \mathrm{~mm}$ occluded, including 14 within the treatment zone.

\section{Combination Therapies TACE and Ablation}

Early-stage $\mathrm{HCC}$ is primarily treated with definitive therapies such as transplantation, resection, or ablation in patients with preserved liver function. ${ }^{47}$ As patient outcomes improved with these treatments, interest developed for combining transarterial chemoembolization (TACE) with ablation for unresectable candidates, particularly for larger tumors. ${ }^{48-51}$ The combination of TACE and ablation is not only additive, but also complementary and potentially synergistic. Conceptually, ablation treats the tumor from the inside-out. In contrast, TACE treats the tumor from outside-in based on perfusion, with potential for treating tumor cells and satellite lesions in the vascular distribution of the main tumor mass. Arterial embolization with TACE reduces the intrinsic heat sink within a relatively vascularized tumor, thus theoretically increasing ablation efficiency and ablation zone size. ${ }^{49}$ 
Furthermore, heat from ablation may potentiate chemotherapeutic toxicity to cancer cells.

Comparative series examining the relative efficacy of TACE to combination therapy with TACE and ablation have consistently shown improved tumor and overall survival outcomes with combination therapy relative to TACE alone. ${ }^{51-53}$ Comparison of TACE and ablation to ablation alone in both retrospective and single-center prospective studies has also consistently demonstrated a signal favoring combination therapy with respect to progression-free survival (PFS) and overall survival (OS), particularly with tumors greater than $3 \mathrm{~cm}$ in size. ${ }^{48-51}$ There is less clarity with the benefits of combination therapy with smaller tumors; however, the experience has shown that combination therapy is very well tolerated, especially in those with baseline preserved liver function, with little concern for additional toxicity. ${ }^{52}$ Furthermore, when TACE is performed in a highly selective fashion, the toxicity of combination therapy becomes theoretically even lower.

\section{Ablation and Immunotherapy}

After the introduction of sorafenib as essentially the first systemically delivered agent with efficacy against HCC, there has been interest in seeing whether locoregional therapies could be leveraged with systemically delivered agents to maximize response rates and outcomes. ${ }^{54}$ Early trials assessed the performance of combining sorafenib with locoregional therapies for early and intermediate stage HCC, unfortunately with no clearly defined benefits. The STORM trial showed no benefit for adjuvant sorafenib after resection or ablation, and the SPACE trial showed that sorafenib combined with TACE did not improve outcomes over sorafenib alone in unresectable intermediate stage HCC. ${ }^{39,55}$ Despite these negative early trials, there remained appeal for combined locoregional and systemic therapies to better control the known high recurrence rates for HCC. The advent of immunotherapies with checkpoint inhibitor blockade, including programmed cell death protein-1 (PD-1), its cognate ligand (PD-L1), and cytotoxic T-lymphocyte-associated antigen 4 (CTLA-4), when combined with multi-kinase inhibitors, has recently shown improved efficacy for advanced HCC over sorafenib. ${ }^{56}$

Based on these favorable results, attempts at synergizing locoregional therapy with immunotherapy has rapidly proliferated the clinical trial landscape for HCC, pushing this combination in earlier stages as well. ${ }^{57-60}$ Locoregional therapies have the capability of generating tumor antigens that can work with immune-checkpoint inhibition to enhance an anti-tumor immune response. ${ }^{61}$ Phase III clinical trials are currently underway examining whether combination ablation and systemic/immunotherapy can improve recurrence rates and overall survival in early-stage HCC. ${ }^{57,59}$

\section{Where are We Heading? AR Guidance Systems}

Effective percutaneous ablation is dependent in good part on operator skill and experience. Inadequate targeting of the tumor can result in incomplete ablation and higher rates of marginal recurrence. Accurate device positioning is essential to achieve adequate tumor coverage and therapy ${ }^{62,63}$ Navigation systems (as shown in Figure 1) allow the ability to position ablation devices with high accuracy and treat hard-to-reach lesions, such as those at the dome. ${ }^{64,65}$ Emerging and existing fusion navigation software can provide feedback on tumor location and adjacent anatomical structures that may be difficult to discern during US-guided, CT-guided, or even conebeam CT navigation using a fluoroscopic C-arm. ${ }^{66-69}$ Although tumor and ablation zones are 3D datasets, needle navigation systems as well as ablation planning software are limited to viewing these datasets on 2D monitor screens. However, 3D planning has been shown to be superior to $2 \mathrm{D}$ planning. ${ }^{70}$ Emerging technologies including virtual reality (VR) and augmented reality (AR) allow the capability to stereoscopically view 3D datasets in actual three dimensions. These technologies can be used to display trajectories more intuitively in actual 3D space, resulting in improved spatial understanding as well as procedure execution and safety. ${ }^{71,72}$ However, accurate registration of these trajectories within patients will be essential for 3D-assisted virtual and holographic guidance. Promising results with AR-assisted guidance include decreased procedure time, reduced radiation dose, and enhanced performance of inexperienced operators. $^{73-75}$

\section{Ablation Zone Prediction}

Even when the ablation device has been successfully navigated to the tumor, an inadequate ablation zone can result in incomplete coverage of the tumor. The ablation zone can only be visualized in real time with cryoablation, and even then the visible iceball does not exactly correspond to the ablation zone. Understanding and predicting the expected ablation zone for a single device is complex 


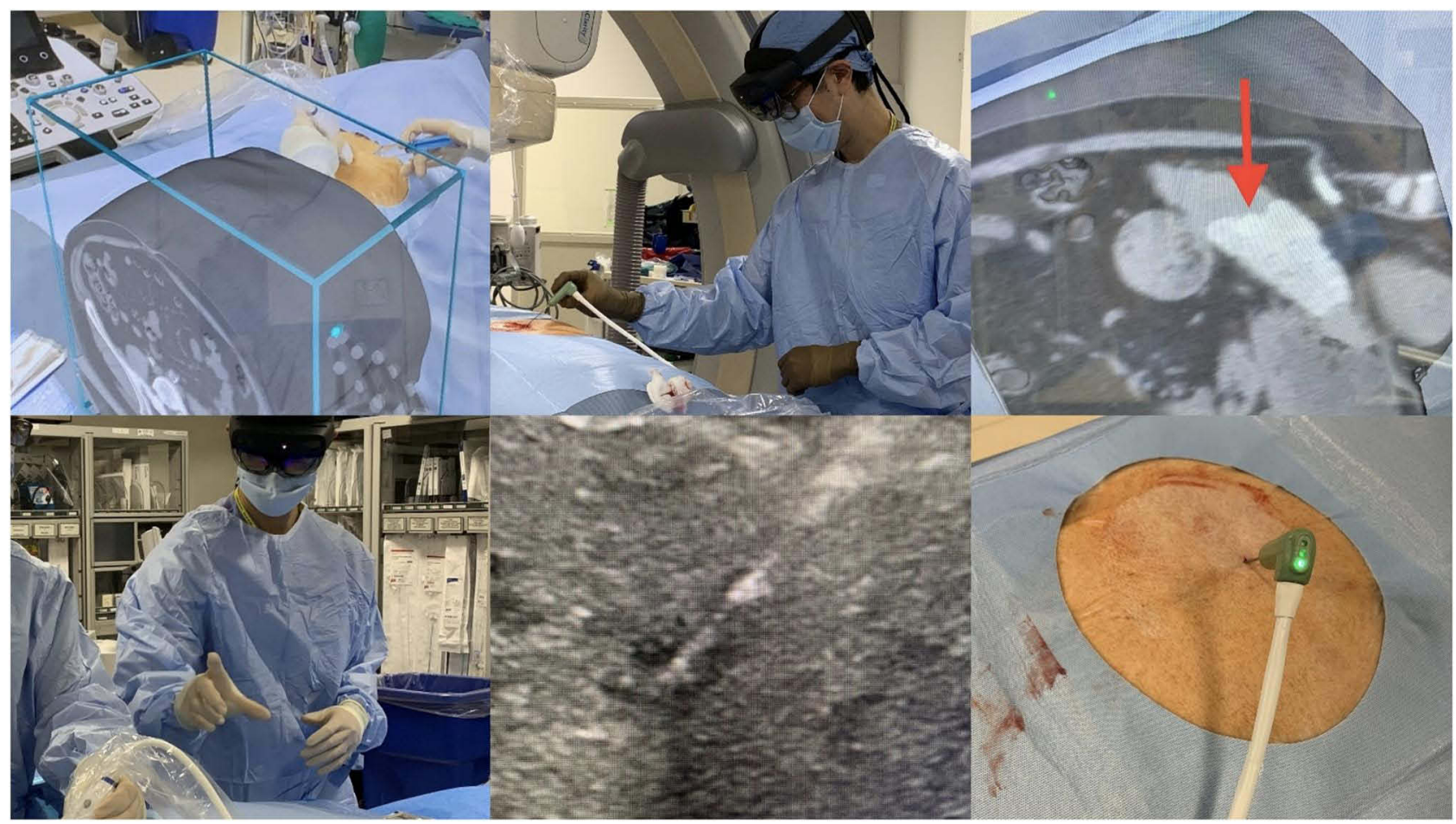

Figure I Microwave ablation of HCC following transarterial chemoembolization (TACE). Augmented reality was used to overlay the post-TACE 3D CT volume within the patient to verify ultrasound location prior to ablation. Red arrow denotes location of $<2 \mathrm{~cm}$ tumor in segment 3 stained with lipiodol. Procedural ultrasound images confirm adequate positioning with the antenna traversing through the center of the tumor.

\section{A}

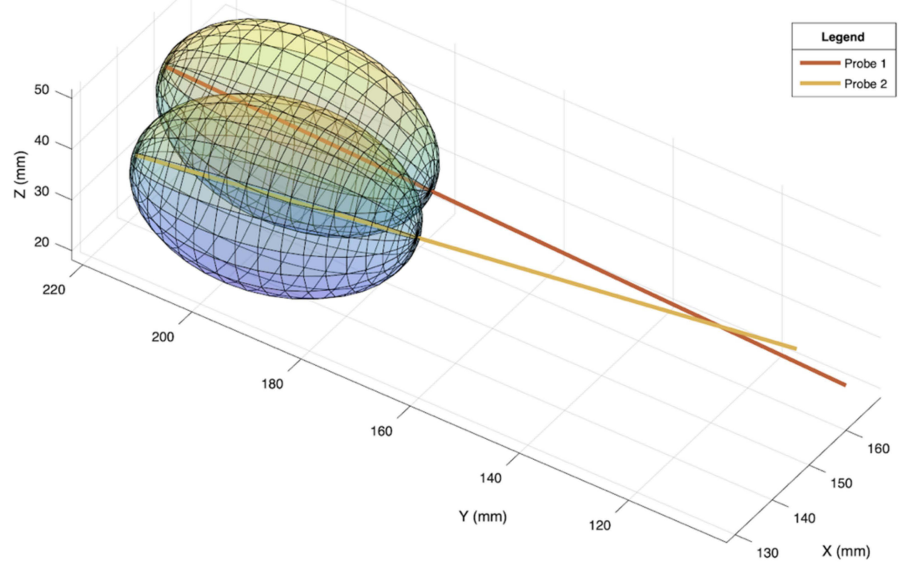

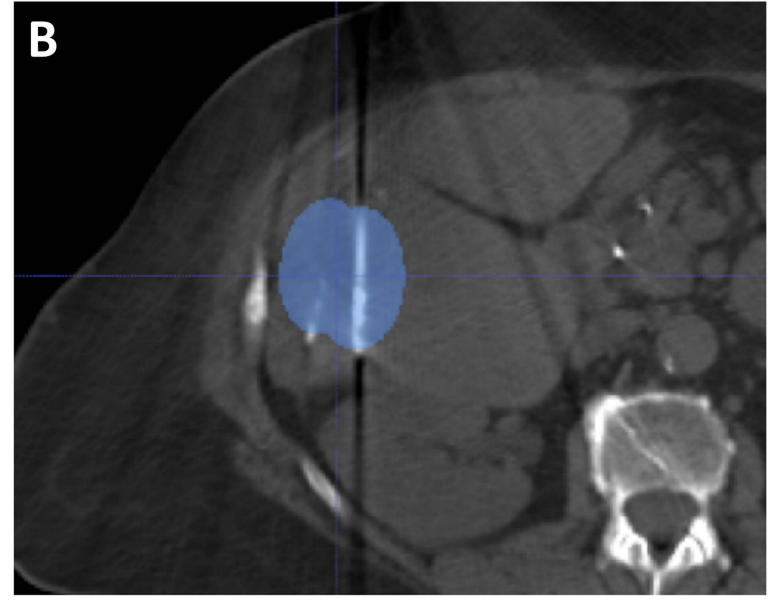

Figure 2 (A) Example case of antenna orientations and predicted Neuwave PR antenna ablation volumes at $65 \mathrm{~W}$ for 10 min. Axes represent pixel locations in isotropic volume. Tips are separated by distance of $15.7 \mathrm{~mm}$ with 8.30 degrees acute angle between the antennas. Total calculated ablation volume is $34,5 \mathrm{I} 2 \mathrm{~mm} 3$. Maximum predicted ablation volume for 2 antennas with $0 \%$ overlap is $44,296 \mathrm{~mm}$. As a result, total volumetric overlap of antennas in configuration above is $44.2 \%$. (B) Theoretical modeled ablation zones overlaid on intraprocedural CT scan. Of note, overlapping ablations were predicted to be additive than synergistic.

and involves interactions among the settings chosen by the operator, tissue density, tissue hydration, and local heat sinks. Additionally, multi-device treatment strategies require precise spacing to achieve tumor bracketing and overlap for synergistic ablation effects that are even more complex to model. There is a growing body of literature examining in vivo ablation zone dimensions to better predict the expected treatment volume. ${ }^{76}$ Ablation planning software (as shown in Figure 2) has become more widely available and can be used to verify optimal trajectories and appropriate tumor coverage to improve technical success and outcomes. ${ }^{77}$ Additional research efforts are focusing 
on more accurately modeling and simulating ablation zones and post-ablation volumetric assessment to improve outcomes. $^{78,79}$

\section{Direct Intra-Tumoral Injection}

The capabilities of anatomically selective tumor delivery, either via transarterial access or direct tumor injection, have led to novel therapeutic agents for direct tumor delivery. These agents include a variety of potential immunomodulating agents and nanoparticle therapeutics. ${ }^{80,81}$ Direct tumor injection or infusion of immunomodulating agents, such as activated dendritic cells, has been explored as a putative mechanism to augment an anti-tumor immune response in the early clinical setting. ${ }^{80,81}$ These studies have shown promise for an increased anti-tumor specific immune response, but with mixed clinical outcomes. ${ }^{80,81}$ Further pre-clinical and clinical studies will undoubtedly increase as excitement for immunomodulation in $\mathrm{HCC}$ continues.

Nanotherapeutics act by diffusing through the perivascular tumor spaces, primarily in a passive fashion termed enhanced permeability and retention (EPR). ${ }^{82,83}$ Additional targeting moieties have been explored to enhance the EPR-based tumor selectivity and accumulation. $^{82-84}$ Nanoplatforms can be used for tumor detection and targeting, selectivity, drug delivery, and for additional therapeutic features such as phototherapy, reactive oxygen species (ROS) generation, magnetic hyperthermia and photoacoustic therapy. ${ }^{82,83,85}$ Several of these features rely on nanoparticle excitation using laser light. While promising, this technology is largely in the pre-clinical setting, with clinical translation requiring likely significant additional research in better understanding the biodistribution and safety profile of these agents before they can be used in a clinically meaningful way. Nevertheless, there is precedence for combination nanotherapeutics with locoregional therapy, as demonstrated in the HEAT trial using thermosensitive liposomal doxorubicin in combination with ablation for multimodal therapy of HCC. ${ }^{86}$ While this study did not meet its primary endpoint, there was signal suggesting improved outcomes in patients who sustained prolonged ( $>45$ minutes) tumor heating with RFA. ${ }^{86}$ The next decade will likely see a rapid burst of research more deeply exploring the potentials of this therapeutic approach.

\section{Other Ablative Modalities}

Several additional ablative modalities for $\mathrm{HCC}$ are being investigated but have not found widespread clinical use. High intensity focused ultrasound (HIFU) uses ultrasound waves from 0.8 to 3.5 megahertz that converge at a set focal point to heat tissue and induce coagulative necrosis. ${ }^{87}$ Early studies have shown promise in treating small $(<3 \mathrm{~cm})$ HCC tumors and combining TACE with HIFU for larger HCC tumors. ${ }^{88,89}$ Complications include skin burns and damage to internal organs due to misregistration of the focal zone or due to patient breathing.

An analogous modality is histotripsy. Like HIFU, histotripsy uses ultrasound waves, but instead of heating tissue, the system uses high intensity high-frequency ultrasound waves to mechanically damage the target tissue. ${ }^{90}$ While still investigational, this technology shows promise both as a direct means of killing tumor tissue, and also as a means of facilitating delivery of novel therapeutics. ${ }^{91}$

Percutaneous laser ablation (LA) is a thermal ablation technique that uses a neodymium:yttrium-aluminumgarnet (Nd:YAG) laser and optical fibers to cause coagulative necrosis. This technique has been shown to be effective at treating $\mathrm{HCC}$, and uses less energy to treat a given tumor volume than RFA or MWA. ${ }^{92,93}$ With recent advances in laser mediated nanoparticle delivery, the next few years may demonstrate a renewed interest in LA. ${ }^{94}$

\section{Conclusion}

Percutaneous ablative techniques are a mainstay of earlystage, unresectable HCC treatment, and in some cases provide potentially definitive treatment for tumors less than $3 \mathrm{~cm}$ in size. Improving percutaneous ablation is an active area of research, including technical refinements, evolution of new technologies, and better determination of treatment end points. Improved guidance systems using augmented reality show promise in allowing for faster and more accurate targeting of tumors. Predicting the final ablation zone remains challenging, but advances in computer modeling are allowing for more accurate preprocedure estimation of the treatment zone. Future clinical trials will hopefully show promise for newer techniques and for leveraging combinatorial therapies. This growing armamentarium will hopefully allow ongoing adaptive tailored treatment for a challenging malignancy. 


\section{Disclosure}

Dr Timothy C Huber reports personal fees for speaking on thyroid nodule RFA from Taewoong Medical, outside the submitted work. Dr Brian Park reports non-financial support from VHA Innovation Ecosystem, grants from RSNA, during the conduct of the study; also reports Clinical Advisory Board for Medivis, outside the submitted work. Dr Khashayar Farsad reports grants from Guerbet, LLC, Exelixis, W.L. Gore; grants, personal fees from Boston Scientific, Cook Medical, Neuwave Medical, Eisai, Genentech, Inquis Medical, Dova Pharmaceuticals, founder of and owns equity for Auxetics, Inc, outside the submitted work; In addition, Dr Khashayar Farsad has a patent auxetic stents for managing venous stenosis pending to Oregon Health and Science University. The authors report no other conflicts of interest in this work.

\section{References}

1. Mittal S, El-Serag HB. Epidemiology of HCC: consider the Population. J Clin Gastroenterol. 2013;47:S2-S6. doi:10.1097/MCG. 0b013e3182872f29

2. Heimbach JK, Kulik LM, Finn RS, et al. AASLD guidelines for the treatment of hepatocellular carcinoma. Hepatology. 2018;67(1):3 58-380. doi:10.1002/hep.29086

3. Wang C, Wang H, Yang W, et al. Multicenter randomized controlled trial of percutaneous cryoablation versus radiofrequency ablation in hepatocellular carcinoma: HEPATOLOGY, Vol. 00, No. X, 2014. Hepatology. 2015;61(5):1579-1590. doi:10.1002/hep.27548

4. Kong W-T, Zhang -W-W, Qiu Y-D, et al. Major complications after radiofrequency ablation for liver tumors: analysis of 255 patients. World J Gastroenterol WJG. 2009;15(21):2651-2656. doi:10.3748/wjg.15.2651

5. Pons F, Varela M, Llovet JM. Staging systems in hepatocellular carcinoma. HPB. 2005;7(1):35-41. doi:10.1080/13651820410024058

6. Livraghi T, Giorgio A, Marin G, et al. Hepatocellular carcinoma and cirrhosis in 746 patients: long-term results of percutaneous ethanol injection. Radiology. 1995;197(1):101-108. doi:10.1148/radiology. 197.1.7568806

7. Pompili M, Nicolardi E, Abbate V, et al. Ethanol injection is highly effective for hepatocellular carcinoma smaller than $2 \mathrm{~cm}$. World J Gastroenterol WJG. 2011;17(26):3126-3132. doi:10.3748/wjg.v17. i26.3126

8. Germani G, Pleguezuelo M, Gurusamy K, Meyer T, Isgrò G, Burroughs AK. Clinical outcomes of radiofrequency ablation, percutaneous alcohol and acetic acid injection for hepatocellular carcinoma: a meta-analysis. J Hepatol. 2010;52(3):380-388. doi:10.1016/j.jhep.20 09.12.004

9. Weis S, Franke A, Berg T, Mössner J, Fleig WE, Schoppmeyer K. Percutaneous ethanol injection or percutaneous acetic acid injection for early hepatocellular carcinoma. Cochrane Database Syst Rev. 2015;2015(1). doi:10.1002/14651858.CD006745.pub3

10. Ahmed M, Brace CL, Lee FT, Goldberg SN. Principles of and advances in percutaneous ablation. Radiology. 2011;258(2):351-369. doi:10.1148/ radiol.10081634

11. Goldberg SN, Gazelle GS, Halpern EF, Rittman WJ, Mueller PR, Rosenthal DI. Radiofrequency tissue ablation: importance of local temperature along the electrode tip exposure in determining lesion shape and size. Acad Radiol. 1996;3(3):212-218. doi:10.1016/s1076-6332(96) 80443-0
12. Koda M, Tokunaga S, Matono $\mathrm{T}$, Sugihara $\mathrm{T}$, Nagahara $\mathrm{T}$, Murawaki Y. Comparison between different thickness umbrella-shaped expandable radiofrequency electrodes (SuperSlim and CoAccess): experimental and clinical study. Exp Ther Med. 2011;2(6):1215-1220. doi:10.3892/etm.2011.347

13. Yu MH, Lee JY, Jun SR, et al. Radiofrequency ablation with an internally cooled monopolar directional electrode: ex vivo and in vivo experimental studies in the liver. Radiology. 2015;278 (2):395-404. doi:10.1148/radiol.2015142269

14. Lin -C-C, Lui K-W, Chen W-T, et al. Switching monopolar radiofrequency ablation improves long-term outcomes of medium-sized hepatocellular carcinoma. Eur Radiol. 2021:1-3. doi:10.1007/ s00330-021-07729-9

15. Cucchetti A, Piscaglia F, Cescon M, et al. Cost-effectiveness of hepatic resection versus percutaneous radiofrequency ablation for early hepatocellular carcinoma. J Hepatol. 2013;59(2):300-307. doi:10.1016/j.jhep.2013.04.009

16. Doyle A, Gorgen A, Muaddi H, et al. Outcomes of radiofrequency ablation as first-line therapy for hepatocellular carcinoma less than $3 \mathrm{~cm}$ in potentially transplantable patients. J Hepatol. 2019;70 (5):866-873. doi:10.1016/j.jhep.2018.12.027

17. N'Kontchou G, Mahamoudi A, Aout M, et al. Radiofrequency ablation of hepatocellular carcinoma: long-term results and prognostic factors in 235 western patients with cirrhosis. Hepatol Baltim Md. 2009;50(5):1475-1483. doi:10.1002/hep.23181

18. Livraghi T, Meloni F, Solbiati L, Zanus G. Complications of microwave ablation for liver tumors: results of a multicenter study. Cardiovasc Intervent Radiol. 2012;35(4):868-874. doi:10.1007/s00 270-011-0241-8

19. Fonseca AZ, Santin S, Gomes LGL, Waisberg J. Complications of radiofrequency ablation of hepatic tumors: frequency and risk factors. World J Hepatol. 2014;6(3):107-113. doi:10.4254/wjh.v6.i3.107

20. Tateishi R, Shiina S, Teratani T, et al. Percutaneous radiofrequency ablation for hepatocellular carcinoma. Cancer. 2005;103(6):12 01-1209. doi:10.1002/cncr.20892

21. Brace CL. Microwave Tissue Ablation: biophysics, Technology and Applications. Crit Rev Biomed Eng. 2010;38(1):65-78. doi:10.1615/ CritRevBiomedEng.v38.i1.60

22. Hinshaw JL, Lubner MG, Ziemlewicz TJ, Lee FT, Brace CL. Percutaneous tumor ablation tools: microwave, radiofrequency, or cryoablation-what should you use and why? Radiogr Rev Publ Radiol Soc N Am Inc. 2014;34(5):1344-1362. doi:10.1148/rg.34 5140054

23. Vogl TJ, Nour-Eldin N-EA, Hammerstingl RM, Panahi B, Naguib NNN. Microwave Ablation (MWA): basics, Technique and Results in Primary and Metastatic Liver Neoplasms - Review Article. ROFO Fortschr Geb Rontgenstr Nuklearmed. 2017;189(11):10 55-1066. doi:10.1055/s-0043-117410

24. Cui R, Yu J, Kuang M, Duan F, Liang P. Microwave ablation versus other interventions for hepatocellular carcinoma: a systematic review and meta-analysis. J Cancer Res Ther. 2020;16(2):379-386. doi:10. 4103/jcrt.JCRT_403_19

25. Erinjeri JP, Clark TWI. Cryoablation: mechanism of Action and Devices. J Vasc Interv Radiol JVIR. 2010;21(8 Suppl):S187-S191. doi:10.1016/j.jvir.2009.12.403

26. Peng P, Hu H, Liu P, Xu LX. Neoantigen-specific CD4+ T-cell response is critical for the therapeutic efficacy of cryo-thermal therapy. J Immunother Cancer. 2020;8(2):e000421. doi:10.1136/jitc-2019-000421

27. Rong G, Bai W, Dong Z, et al. Long-Term Outcomes of Percutaneous Cryoablation for Patients with Hepatocellular Carcinoma within Milan Criteria. PLoS One. 2015;10(4):e0123065. doi:10.1371/journal.pone. 0123065

28. Dunne RM, Shyn PB, Sung JC, et al. Percutaneous treatment of hepatocellular carcinoma in patients with cirrhosis: a comparison of the safety of cryoablation and radiofrequency ablation. Eur J Radiol. 2014;83(4):632-638. doi:10.1016/j.ejrad.2014.01.007 
29. Seifert JK, Stewart GJ, Hewitt PM, Bolton EJ, Junginger T, Morris DL. Interleukin-6 and Tumor Necrosis Factor- $\alpha$ Levels following Hepatic Cryotherapy: association with Volume and Duration of Freezing. World J Surg. 1999;23(10):1019-1026. doi:10.1007/s002689900617

30. Jansen M, van Hillegersberg R, Schoots I, et al. Cryoablation induces greater inflammatory and coagulative responses than radiofrequency ablation or laser induced thermotherapy in a rat liver model. Surgery. 2009;147(5):686-695. doi:10.1016/j.surg.2009.10.053

31. Glazer DI, Tatli S, Shyn PB, Vangel MG, Tuncali K, Silverman SG. Percutaneous Image-Guided Cryoablation of Hepatic Tumors: single-Center Experience With Intermediate to Long-Term Outcomes. AJR Am J Roentgenol. 2017;209(6):1381-1389. doi:10. 2214/AJR.16.17582

32. Littrup PJ, Aoun HD, Adam B, Krycia M, Prus M, Shields A. Percutaneous cryoablation of hepatic tumors: long-term experience of a large U.S. series. Abdom Radiol N Y. 2016;41(4):767-780. doi:10.1007/s00261-016-0687-x

33. Cornelis FH, Cindrič H, Kos B, et al. Peri-Tumoral Metallic Implants Reduces the Efficacy of Irreversible Electroporation for the Ablation of Colorectal Liver Metastases. Cardiovasc Intervent Radiol. 2020;43 (1):84-93. doi:10.1007/s00270-019-02300-y

34. Ruarus AH, Barabasch A, Catalano O, et al. Irreversible Electroporation for Hepatic Tumors: protocol Standardization Using the Modified Delphi Technique. J Vasc Interv Radiol. 2020;31 (11):1765-1771.e15. doi:10.1016/j.jvir.2020.02.030

35. Verloh N, Jensch I, Lürken L, et al. Similar complication rates for irreversible electroporation and thermal ablation in patients with hepatocellular tumors. Radiol Oncol. 2019;53(1):116-122. doi:10. 2478/raon-2019-0011

36. Kalra N, Gupta P, Gorsi U, et al. Irreversible electroporation for unresectable hepatocellular carcinoma: initial experience. Cardiovasc Intervent Radiol. 2019;42(4):584-590. doi:10.1007/s00 270-019-02164-2

37. Zeng J, Liu G, Li Z, et al. The safety and efficacy of irreversible electroporation for large hepatocellular carcinoma. Technol Cancer Res Treat. 2017;16(1):120-124. doi:10.1177/1533034616 676445

38. Padia SA, Johnson GE, Yeung RS, Park JO, Hippe DS, Kogut MJ. Irreversible Electroporation in Patients with Hepatocellular Carcinoma: immediate versus Delayed Findings at MR Imaging. Radiology. 2016;278(1):285-294. doi:10.1148/radiol.2015150031

39. Lencioni R, Izzo F, Crocetti L, et al. Abstract No LB12: a prospective, multicenter Phase II clinical trial using irreversible electroporation for the treatment of early stage HCC. J Vasc Interv Radiol. 2012;23(8):1114. doi:10.1016/j.jvir.2012.05.018

40. Freeman E, Cheung W, Kavnoudias H, Majeed A, Kemp W, Roberts SK. Irreversible Electroporation For Hepatocellular Carcinoma: longer-Term Outcomes At A Single Centre. Cardiovasc Intervent Radiol. 2021;44(2):247-253. doi:10.1007/s00270-02002666-4

41. Sutter O, Calvo J, N'Kontchou G, et al. Safety and Efficacy of Irreversible Electroporation for the Treatment of Hepatocellular Carcinoma Not Amenable to Thermal Ablation Techniques: a Retrospective Single-Center Case Series. Radiology. 2017;284 (3):877-886. doi:10.1148/radiol.2017161413

42. Bhutiani N, Philips P, Scoggins CR, McMasters KM, Potts MH, Martin RCG. Evaluation of tolerability and efficacy of irreversible electroporation (IRE) in treatment of Child-Pugh B (7/8) hepatocellular carcinoma (HCC). HPB. 2016;18(7):593-599. doi:10.1016/j. hpb.2016.03.609

43. Zimmerman A, Grand D, Charpentier KP. Irreversible electroporation of hepatocellular carcinoma: patient selection and perspectives. J Hepatocell Carcinoma. 2017;4:49-58. doi:10.2147/JHC.S129063

44. Kambakamba P, Bonvini JM, Glenck M, et al. Intraoperative adverse events during irreversible electroporation-a call for caution. Am J Surg. 2016;212(4):715-721. doi:10.1016/j.amjsurg.2016.07.001
45. Narayanan G, Bhatia S, Echenique A, Suthar R, Barbery K, Yrizarry J. Vessel patency post irreversible electroporation. Cardiovasc Intervent Radiol. 2014;37(6):1523-1529. doi:10.1007/ s00270-014-0988-9

46. Distelmaier M, Barabasch A, Heil P, et al. Midterm Safety and Efficacy of Irreversible Electroporation of Malignant Liver Tumors Located Close to Major Portal or Hepatic Veins. Radiology. 2017;285 (3):1023-1031. doi:10.1148/radiol.2017161561

47. Yang JD, Hainaut P, Gores GJ, Amadou A, Plymoth A, Roberts LR. A global view of hepatocellular carcinoma: trends, risk, prevention and management. Nat Rev Gastroenterol Hepatol. 2019;16(10):5 89-604. doi:10.1038/s41575-019-0186-y

48. Jiang C, Cheng G, Liao M, Huang J. Individual or combined transcatheter arterial chemoembolization and radiofrequency ablation for hepatocellular carcinoma: a time-to-event meta-analysis. World J Surg Oncol. 2021;19. doi:10.1186/s12957-021-02188-4

49. Morimoto M, Numata K, Kondou M, Nozaki A, Morita S, Tanaka K. Midterm outcomes in patients with intermediate-sized hepatocellular carcinoma. Cancer. 2010;116(23):5452-5460. doi:10.1002/cncr.25 314

50. Wang T, Lu X-J, Chi J-C, et al. Microwave ablation of hepatocellular carcinoma as first-line treatment: long term outcomes and prognostic factors in 221 patients. Sci Rep. 2016;6(1):32728. doi:10.1038/ srep32728

51. Ni J, Liu S, Xu L, Sun H, Chen Y. Transarterial chemoembolization combined with percutaneous radiofrequency ablation versus TACE and PRFA monotherapy in the treatment for hepatocellular carcinoma: a meta-analysis. J Cancer Res Clin Oncol. 2013;139(4):65 3-659. doi:10.1007/s00432-012-1369-x

52. Hyun D, Cho SK, Shin SW, et al. Early Stage Hepatocellular Carcinomas Not Feasible for Ultrasound-Guided Radiofrequency Ablation: comparison of Transarterial Chemoembolization Alone and Combined Therapy with Transarterial Chemoembolization and Radiofrequency Ablation. Cardiovasc Intervent Radiol. 2016;39 (3):417-425. doi:10.1007/s00270-015-1194-0

53. Yang D, Luo K, Liu H, et al. Meta-analysis of transcatheter arterial chemoembolization plus radiofrequency ablation versus transcatheter arterial chemoembolization alone for hepatocellular carcinoma. Oncotarget. 2016;8(2):2960-2970. doi:10.18632/oncotarget.13813

54. Llovet JM, Hilgard P, de Oliveira AC, et al. Sorafenib in advanced hepatocellular carcinoma. N Engl J Med. 2008;359:378-390.

55. Bruix J, Takayama T, Mazzaferro V, et al. Adjuvant sorafenib for hepatocellular carcinoma after resection or ablation (STORM): a Phase 3, randomised, double-blind, placebo-controlled trial. Lancet Oncol. 2015;16 (13):1344-1354. doi:10.1016/S1470-2045(15)00198-9

56. Finn RS, Qin S, Ikeda M, et al. Atezolizumab plus bevacizumab in unresectable hepatocellular carcinoma. $N$ Engl J Med. 2020;382 (20):1894-1905. doi:10.1056/NEJMoa1915745

57. Farsad K, Nabavizadeh N, Kardosh A, Jou JH, Naugler WE, Kolbeck KJ. Combined locoregional and systemic therapy for advanced hepatocellular carcinoma: finally, the future is obscure. Ann Transl Med. 2020;8(24):1700. doi:10.21037/atm-20-4164

58. Kole C, Charalampakis N, Tsakatikas S, et al. Immunotherapy for hepatocellular carcinoma: a 2021 update. Cancers. 2020;12 (10):2859. doi:10.3390/cancers 12102859

59. Llovet JM, De Baere T, Kulik L, et al. Locoregional therapies in the era of molecular and immune treatments for hepatocellular carcinoma. Nat Rev Gastroenterol Hepatol. 2021;18(5):293-313. doi:10.1038/s41575-020-00395-0

60. Kudo M. Immuno-Oncology Therapy for Hepatocellular Carcinoma: current Status and Ongoing Trials. Liver Cancer. 2019;8(4):221-238. doi:10.1159/000501501

61. Singh P, Toom S, Avula A, Kumar V, Rahma OE. The Immune Modulation Effect of Locoregional Therapies and Its Potential Synergy with Immunotherapy in Hepatocellular Carcinoma. J Hepatocell Carcinoma. 2020;7:11-17. doi:10.2147/JHC.S187121 
62. Wood BJ, Kruecker J, Abi-Jaoudeh N, et al. Navigation Systems for Ablation. J Vasc Interv Radiol. 2010;21(8):S257-S263. doi:10.1016/ j.jvir.2010.05.003

63. Maybody M, Carsten S, Solomon SB. Overview of Navigation Systems in Image-Guided Interventions. Tech Vasc Interv Radiol. 2013;16(3):136-143. doi:10.1053/j.tvir.2013.02.008

64. Beyer LP, Wiggermann P. Planning and guidance: new tools to enhance the human skills in interventional oncology. Diagn Interv Imaging. 2017;98(9):583-588. doi:10.1016/j.diii.2017.07.004

65. Rouchy R, Moreau-Gaudry A, Chipon E, et al. Evaluation of the clinical benefit of an electromagnetic navigation system for CT-guided interventional radiology procedures in the thoraco-abdominal region compared with conventional CT guidance (CTNAV II): study protocol for a randomised controlled trial. Trials. 2017;18(1):306. doi:10.1186/s13063-017-2049-6

66. Abi-Jaoudeh $\mathrm{N}$, Kobeiter $\mathrm{H}$, Xu S, Wood BJ. Image fusion during vascular and nonvascular image-guided procedures. Tech Vasc Interv Radiol. 2013;16(3):168-176. doi:10.1053/j.tvir.2013.02.012

67. Abi-Jaoudeh N, Venkatesan AM, Van der Sterren W, Radaelli A, Carelsen B, Wood BJ. Clinical Experience with Cone-Beam CT Navigation for Tumor Ablation. J Vasc Interv Radiol. 2015;26 (2):214-219. doi:10.1016/j.jvir.2014.10.049

68. Muglia R, Solbiati L. New technological advancements for interventional oncology. Chin Clin Oncol. 2019;8(6):65. doi:10.21037/cco.2019.10.06

69. Solbiati M, Passera KM, Goldberg SN, et al. A Novel CT to Cone-Beam CT Registration Method Enables Immediate Real-Time Intraprocedural Three-Dimensional Assessment of Ablative Treatments of Liver Malignancies. Cardiovasc Intervent Radiol. 2018;41(7):1049-1057. doi:10.1007/s00270-018-1909-0

70. Liu F, Liang P, Yu X, et al. A three-dimensional visualisation preoperative treatment planning system in microwave ablation for liver cancer: a preliminary clinical application. Int J Hyperth. 2013;29 (7):671-677. doi:10.3109/02656736.2013.834383

71. Al-Nimer S, Hanlon A, Cho K, et al. 3D Holographic Guidance and Navigation for Percutaneous Ablation of Solid Tumor. J Vasc Interv Radiol JVIR. 2020;31(3):526-528. doi:10.1016/j.jvir.2019.09.027

72. Park BJ, Hunt SJ, Martin C, Nadolski GJ, Wood BJ, Gade TP. Augmented and Mixed Reality: technologies for Enhancing the Future of IR. J Vasc Interv Radiol JVIR. 2020;31(7):1074-1082. doi:10.1016/j.jvir.2019.09.020

73. Solbiati M, Passera KM, Rotilio A, et al. Augmented reality for interventional oncology: proof-of-concept study of a novel high-end guidance system platform. Eur Radiol Exp. 2018;2(1):18. doi:10.1186/s41747-018-0054-5

74. Park BJ, Hunt SJ, Nadolski GJ, Gade TP. Augmented reality improves procedural efficiency and reduces radiation dose for CT-guided lesion targeting: a phantom study using HoloLens 2. Sci Rep. 2020;10(1):18620. doi:10.1038/s41598-020-75676-4

75. Long DJ, Li M, De Ruiter QMB, et al. Comparison of Smartphone Augmented Reality, Smartglasses Augmented Reality, and 3D CBCT-guided Fluoroscopy Navigation for Percutaneous Needle Insertion: a Phantom Study. Cardiovasc Intervent Radiol. 2021;44 (5):774-781. doi:10.1007/s00270-020-02760-7

76. Huber TC, Miller G, Patrie J, Angle JF. Relationship of Antenna Work and Ablation Cavity Volume Following Percutaneous Microwave Ablation of Hepatic Tumors. J Vasc Interv Radiol. 2021;32(4):536-543. doi:10.1016/j.jvir.2020.12.012

77. Lyons GR, Pua BB. Ablation Planning Software for Optimizing Treatment: challenges, Techniques, and Applications. Tech Vasc Interv Radiol. 2019;22(1):21-25. doi:10.1053/j.tvir.2018.10.005

78. Wang XR, Gao HJ, Wu SC, Jiang T, Zhou ZH, Bai YP. Numerical evaluation of ablation zone under different tip temperatures during radiofrequency ablation. Math Biosci Eng MBE. 2019;16 (4):2514-2531. doi:10.3934/mbe.2019126
79. Solbiati M, Muglia R, Goldberg SN, et al. A novel software platform for volumetric assessment of ablation completeness. Int J Hyperth. 2019;36(1):337-343. doi:10.1080/02656736.2019.1569267

80. Mizukoshi E, Nakamoto Y, Arai K, et al. Enhancement of tumor-specific T-cell responses by transcatheter arterial embolization with dendritic cell infusion for hepatocellular carcinoma. Int $J$ Cancer. 2010;126(9):2164-2174. doi:10.1002/ijc.24882

81. Rizell M, Sternby Eilard M, Andersson M, Andersson B, KarlssonParra A. Phase 1 Trial With the Cell-Based Immune Primer Ilixadencel, Alone, and Combined With Sorafenib, in Advanced Hepatocellular Carcinoma. Front Oncol. 2019;9:19. doi:10.3389/ fonc. 2019.00019

82. Han X, Xu K, Taratula O, Farsad K. Applications of nanoparticles in biomedical imaging. Nanoscale. 2019;11(3):799-819. doi:10.1039/ C8NR07769J

83. Kong F-H, Ye Q-F, Miao X-Y, et al. Current status of sorafenib nanoparticle delivery systems in the treatment of hepatocellular carcinoma. Theranostics. 2021;11(11):5464-5490. doi:10.7150/thno. 54822

84. Feng S, Zhou J, Li Z, et al. Sorafenib encapsulated in nanocarrier functionalized with glypican-3 specific peptide for targeted therapy of hepatocellular carcinoma. Colloids Surf B Biointerfaces. 2019; 184:110498. doi:10.1016/j.colsurfb.2019.110498

85. Taratula OR, Taratula O, Han X, et al. Transarterial Delivery of a Biodegradable Single-Agent Theranostic Nanoprobe for Liver Tumor Imaging and Combinatorial Phototherapy. J Vasc Interv Radiol JVIR. 2019;30(9):1480-1486.e2. doi:10.1016/j.jvir.2019.03. 004

86. Tak WY, Lin S-M, Wang Y, et al. Phase III HEAT study adding lyso-thermosensitive liposomal doxorubicin to radiofrequency ablation in patients with unresectable hepatocellular carcinoma lesions. Clin Cancer Res. 2018;24(1):73-83. doi:10.1158/1078-0432.CCR16-2433

87. Cheung TT, Ma KW, She WH. A review on radiofrequency, microwave and high-intensity focused ultrasound ablations for hepatocellular carcinoma with cirrhosis. Hepatobiliary Surg Nutr. 2021;10 (2):193-209. doi:10.21037/hbsn.2020.03.11

88. Cheung TT, Fan ST, Chu FSK, et al. Survival analysis of high-intensity focused ultrasound ablation in patients with small hepatocellular carcinoma. HPB. 2013;15(8):567-573. doi:10.1111/hpb.12025

89. Li C, Zhang W, Zhang R, Zhang L, Wu P, Zhang F. Therapeutic effects and prognostic factors in high-intensity focused ultrasound combined with chemoembolisation for larger hepatocellular carcinoma. Eur J Cancer. 2010;46(13):2513-2521. doi:10.1016/j.ejca.2010.06.015

90. Roberts WW. Development and Translation of Histotripsy: current Status and Future Directions. Curr Opin Urol. 2014;24(1):104-110. doi:10.1097/MOU.0000000000000001

91. Vlaisavljevich E, Durmaz YY, Maxwell A, ElSayed M. NanodropletMediated Histotripsy for Image-guided Targeted Ultrasound Cell Ablation. Theranostics. 2013;3(11):851-864. doi:10.7150/thno.6717

92. Francica G, Petrolati A, Di Stasio E, Pacella S, Stasi R, Pacella CM. Effectiveness, Safety, and Local Progression After Percutaneous Laser Ablation for Hepatocellular Carcinoma Nodules up to $4 \mathrm{~cm}$ Are Not Affected by Tumor Location. Am J Roentgenol. 2012;199 (6):1393-1401. doi:10.2214/AJR.11.7850

93. Costanzo GGD, Tortora R, D’Adamo G, et al. Radiofrequency ablation versus laser ablation for the treatment of small hepatocellular carcinoma in cirrhosis: a randomized trial. J Gastroenterol Hepatol. 2015;30(3):559-565. doi:10.1111/jgh.12791

94. Cantu T, Walsh K, Pattani VP, et al. Conductive polymer-based nanoparticles for laser-mediated photothermal ablation of cancer: synthesis, characterization, and in vitro evaluation. Int J Nanomed. 2017;12:615-632. doi:10.2147/IJN.S116583 


\section{Publish your work in this journal}

The Journal of Hepatocellular Carcinoma is an international, peerreviewed, open access journal that offers a platform for the dissemination and study of clinical, translational and basic research findings in this rapidly developing field. Development in areas including, but not limited to, epidemiology, vaccination, hepatitis therapy, pathology

and molecular tumor classification and prognostication are all considered for publication. The manuscript management system is completely online and includes a very quick and fair peer-review system, which is all easy to use. Visit http://www.dovepress.com/ testimonials.php to read real quotes from published authors.

Submit your manuscript here: https://www.dovepress.com/journal-of-hepatocellular-carcinoma-journal 